\title{
Monitoring and forecasting fault development at actively forming calderas: An experimental study
}

\author{
Gilles Seropian* and John Stix \\ Department of Earth and Planetary Sciences, McGill University, 3450 University Street, Montreal, Quebec H3A 0E8, Canada
}

\begin{abstract}
Caldera collapse events can be sudden and violent in the case of large explosive volcanic eruptions, or incremental in the case of long-lived eruptions. Faults nucleating during collapse are associated with seismic activity, yet the kinematic behavior of newly formed faults is poorly constrained. We conducted a series of novel sandbox experiments using piezoelectric sensors to monitor stress perturbations during a caldera collapse. We found excellent spatial and temporal correlations among (1) fault nucleation, inferred from the stress sensor data, (2) the appearance of faults on the surface, and (3) final fault structure, obtained via cross sections. We estimated fault propagation rates for early inner faults and found that these rates increase with increasing magma evacuation rates. We applied our experimental results to seismic data from natural caldera-forming episodes in order to estimate rates of fault propagation for these systems. Our experiments are consistent with en masse caldera collapse events, such as at Mount Katmai (Alaska, USA) in A.D. 1912 and Mount Pinatubo (Philippines) in 1991.
\end{abstract}

\section{INTRODUCTION}

Calderas are large depressions found in all types of volcanic settings. A caldera-forming eruption involves significant hazards on local, regional, and global scales, hence the importance to study and understand the mechanics of such events. Faults forming during caldera collapses play a fundamental role, as they control the locations of the eruptive vents as well as the nature and rate of caldera subsidence.

Notable advances in our knowledge of caldera formation have occurred in the past few decades, thanks to field (e.g., Geshi et al., 2002), experimental (e.g., Roche et al., 2000), theoretical (e.g., Roche and Druitt, 2001), and integrated studies (e.g., Stix and Kobayashi, 2008). Nevertheless, a number of fundamental problems have yet to be solved. When do faults nucleate at depth and how fast do they propagate? How is seismic energy released from the caldera in a spatial and temporal sense?

We address these questions through a series of novel analogue experiments, focusing on the effect of evacuation rate on the kinematics of collapse. We instrumented our experiments with a series of sensors designed to record fault development as a function of both time and space. We then compare our results to historical caldera-forming events.

\section{METHODOLOGY}

\section{Experimental Apparatus}

Our experimental setup is composed of a 1-m-diameter, 1.4-m-high, cylindrical tank filled

*Current address: School of Earth Sciences, University of Bristol, Wills Memorial Building, Queens Road, Bristol BS8 1RJ, UK. with brown sand. We used a water-filled rubber bladder to represent the magma chamber. Once inflated, the bladder is an oblate ellipsoid $30 \mathrm{~cm}$ wide and $15 \mathrm{~cm}$ thick at the center, with an initial volume of $5 \mathrm{~L}$. The bladder was buried so that its top was $\sim 7 \mathrm{~cm}$ beneath the surface, thus yielding a roof aspect ratio (roof thickness / bladder diameter) of 0.23 . These conditions represent a natural magma chamber whose roof lies at $\sim 2$ $\mathrm{km}$ below the surface. Full details of the experimental setup can be found in the GSA Data Repository ${ }^{1}$ and in Coumans and Stix (2016).

We used piezoelectric sensors to monitor changes in the interior of our sandbox. The sensors feature piezoelectric transducers, which produce an electric signal in response to differential stresses. Thus, our sensors record stress variations. Three sensors were placed on a horizontal line and buried about halfway between the top of the bladder and the surface. The first sensor was located directly above the center of the bladder, and the other two were placed above the edge of the bladder. We refer to them as center, east, and west sensors, respectively.

In running an experiment, water was pumped out of the bladder, simulating an eruption and triggering the caldera collapse. The evacuation rate was controlled so that, regardless of the duration of the experiment, the final volume of water evacuated from the bladder was $50 \%$ of

'GSA Data Repository item 2018005, additional details about the experimental setup and the sensors used, as well as spectrograms and close-up views of the sensors signals, and information about the fault propagation direction, is available online at http:// www.geosociety.org/datarepository/2018/ or on request from editing@geosociety.org. the initial volume. After each experiment, we sectioned the caldera to obtain pictures of cross sections.

A key objective was to compare fault development for a caldera that formed rapidly at relatively high evacuation rates versus one that formed more slowly at reduced evacuation rates. Hence the duration of our first experiment (A) was $2.5 \mathrm{~min}$ with an evacuation rate of $1 \mathrm{~L} \mathrm{~min}^{-1}$; for the second experiment (B) the duration was 12.5 min with an evacuation rate of $0.2 \mathrm{~L} \mathrm{~min}^{-1}$.

\section{Scaling Relations}

Every parameter of the experiment was carefully scaled to accurately reproduce natural caldera collapses (Sanford, 1959). For each fundamental dimension $X$, we define a ratio $X^{*}=$ $X_{\text {model }} / X_{\text {nature }}$. Our length ratio is $L^{*}=3.5 \times 10^{-5}$, so that our $35 \mathrm{~cm}$ calderas represent a $10-\mathrm{km}$ diameter caldera in nature. Gravitational conditions are identical in nature and in our model, thus $g^{*}=L^{*} T^{*-2}=1$ ( $T$ is time), yielding a time scaling ratio of $T^{*}=\left(L^{*}\right)^{1 / 2}=5.9 \times 10^{-3}$. Dry sand has a bulk density of $1650 \mathrm{~kg} \mathrm{~m}^{-3}$, whereas the density of volcanic rocks is $\sim 2800 \mathrm{~kg} \mathrm{~m}^{-3}$. Hence our density ratio is $\rho^{*}=0.59$. The density ratio for the fluids (water with density of $1000 \mathrm{~kg}$ $\mathrm{m}^{-3}$ and magma with density of $2200 \mathrm{~kg} \mathrm{~m}^{-3}$ ) is 0.45 , indicating that the two densities are within the same order of magnitude. The stress ratio is $\sigma^{*}=\rho^{*} g^{*} L^{*}=2 \times 10^{-5}$. The natural cohesion of volcanic rocks is $\sim 10^{7} \mathrm{~Pa}$ (Hoek et al., 1995) but can be as low as $10^{6} \mathrm{~Pa}$ (Schultz, 1996). It is difficult to precisely determine our sand cohesion, but it is safe to assume it is within 0-100 $\mathrm{Pa}$, which is reasonable for our purpose. Finally, the viscosity ratio is given by $\mu^{*}=\sigma^{*} \mathrm{~T}^{*} \approx 10^{-7}$. Because $\mu_{\text {water }}=10^{-3} \mathrm{~Pa} \cdot \mathrm{s}$, this represents a natural magma with a viscosity of $10^{4} \mathrm{~Pa} \cdot \mathrm{s}$.

\section{Limitations}

We focus solely on fault nucleation and propagation as the caldera develops, so our experiments did not include any preexisting structural discontinuities, although they are present in nature because of magma chamber inflation or local tectonics. Furthermore, our experiments did not include any temperature, magma rheology, ring dike, or vent migration effects, which can influence the collapse dynamics (e.g., Kennedy et al., 2008). However, our simplified approach 

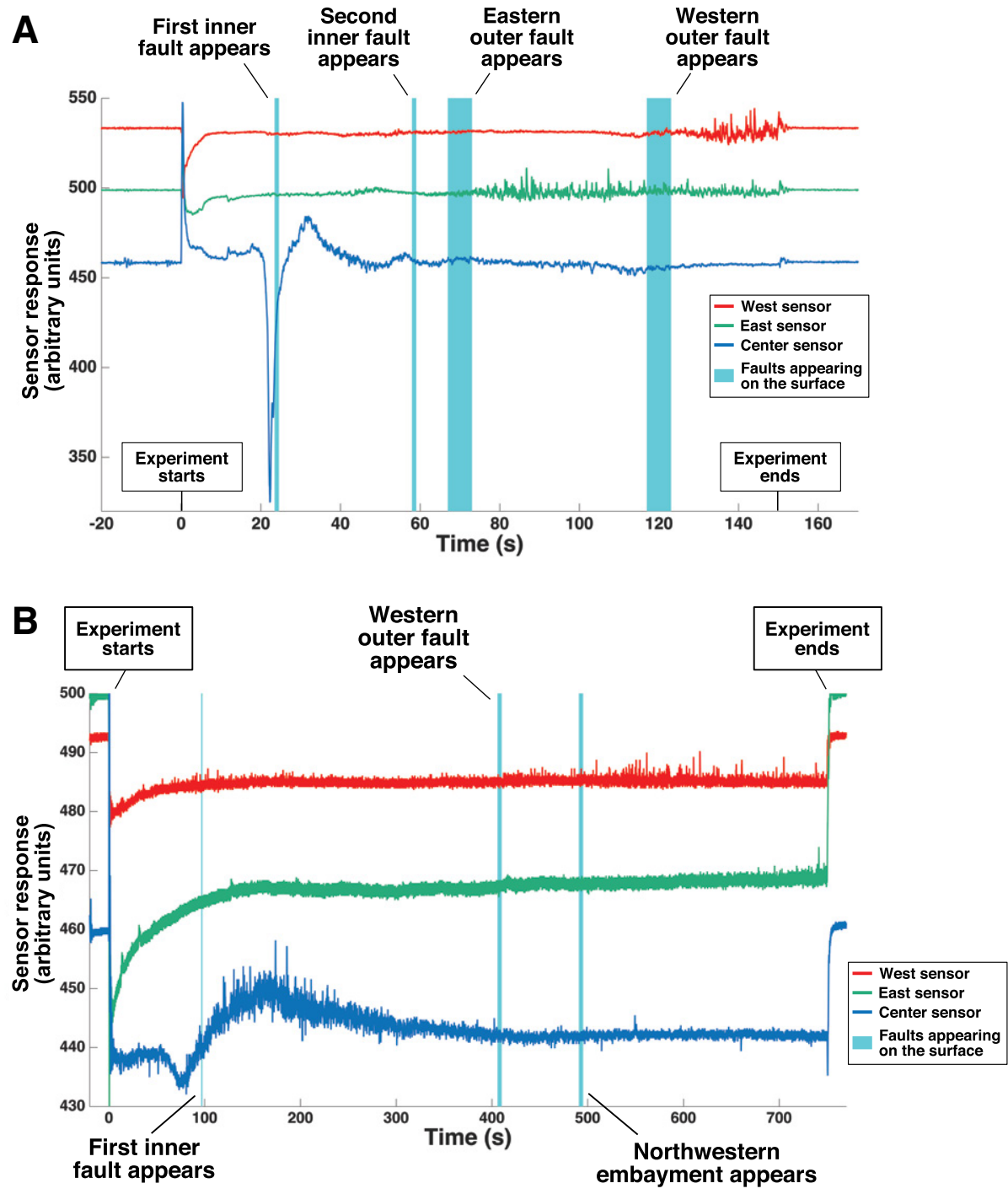

Figure 1. Stress evolution during experiment $A(A)$ and experiment $B(B)$. Times at which faults of interest appear on surface are indicated. Green color corresponds to eastern features, and red corresponds to western features.

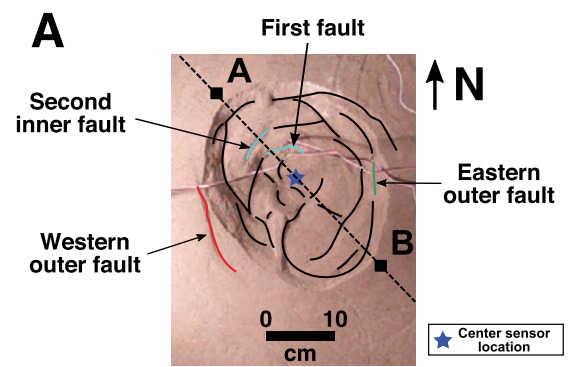

B

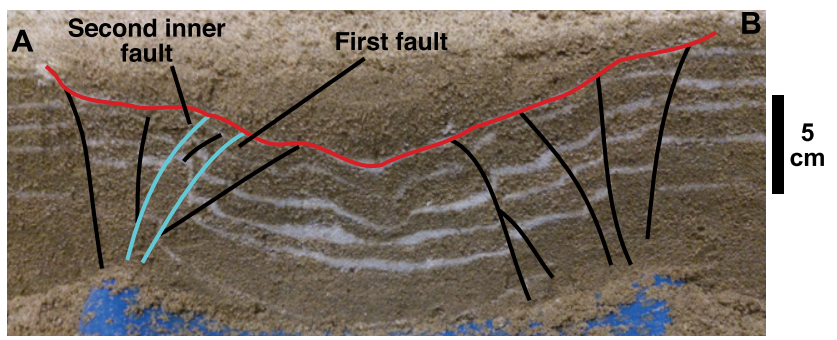

allows us to focus on and isolate the caldera response to evacuation of the magma chamber. The stress changes recorded by the piezometers are not directly equivalent to ground motion recorded by seismometers at real calderas. Nevertheless, they provide a good approximation of and guide to the locations of seismic events in nature. Lastly, our magma evacuation procedure did not include eruption and accumulation of material at the surface. Although such processes are likely to influence caldera subsidence, our procedure focuses directly on how the roof of the reservoir responds to progressive evacuation of the reservoir.

\section{RESULTS}

Both experiments followed the four general stages commonly observed and summarized by Acocella (2007). Deformation starts with broad sagging, before the first inner faults appear. Peripheral regions then start subsiding, and finally, outer faults appear on the surface. The output from the stress sensors is presented in Figure 1 for both experiments; the sensor units are arbitrary. For each experiment, we studied the most significant faults and noted the time at which they appeared on the surface. For experiment $\mathrm{A}$, we picked the first fault appearing, the second inner fault, the eastern outer fault, and the western outer fault. For experiment B, we used the first fault, the western outer fault, and a large northwestern embayment. For both experiments, the first fault was the most obvious and significant feature as it appeared on the surface.

In experiment $\mathrm{A}$, the signals from the three sensors are flat and steady before the experiment starts (Fig. 1A). All three sensors record a large offset as the experiment is initiated by the pump being turned on. The signals return to a flat, steady pattern after a few seconds. The first noticeable event occurs in the center sensor signal; after a few small spikes, a very large drop occurs, starting at $20.5 \mathrm{~s}$. The first fault also appears in the central area between 23.5 and $24.5 \mathrm{~s}$ (Fig. 2A). This drop is followed by a positive signal peaking at $\sim 33 \mathrm{~s}$ and then decaying for $\sim 20 \mathrm{~s}$. A second smaller peak is observed at $\sim 56 \mathrm{~s}$, and the second set of inner faults appear on the surface at 58-59 s. The center sensor signal then becomes flat, with progressively fewer perturbations until the end of the experiment. The east sensor is the next to record a period of unrest. From $75 \mathrm{~s}$ until the end of the experiment, the deviations from the baseline signal are much larger, with maximum amplitudes between 85 and $110 \mathrm{~s}$. The eastern outer fault appears between 67 and 70 s. From $125 \mathrm{~s}$ until the end of the experiment, the west sensor shows a period of high activity relative to its baseline. This coincides with the appearance of the western outer fault at the surface between 117 and $120 \mathrm{~s}$. Outer faults propagate all around the caldera until $\sim 125 \mathrm{~s}$. 
After this time, the caldera continues to deepen but ceases its outward growth. All three sensors return to their initial state after the experiment ends at $150 \mathrm{~s}$.

In experiment $\mathrm{B}$, the three sensor signals are flat before the start of the experiment. Large perturbations are observed as the experiment starts. At $55 \mathrm{~s}$, the center sensor signal starts dropping and forms a very large trough with a minimum value at $\sim 80 \mathrm{~s}$. The first fault appears on the surface at $96-98 \mathrm{~s}$. This is followed by a positive signal, which peaks at $170 \mathrm{~s}$, then slowly decays to $\sim 415 \mathrm{~s}$. The noise level is also much higher than beforehand, especially between 120 and $220 \mathrm{~s}$. The west sensor records a period of activity starting at $500 \mathrm{~s}$ until the end. Western outer faults first appear between 406 and $410 \mathrm{~s}$ and then propagate very slowly. A large embayment appears on the northwestern edge between 491 and $495 \mathrm{~s}$. By $500 \mathrm{~s}$, the caldera is well defined and stops propagating outward. It deepens, however, and the walls become more defined until the end of the experiment. The east sensor records a few medium-amplitude peaks toward the end of the experiment but no largeamplitude signal.

The stress field is not spatially uniform during an experiment (Roche et al., 2000). Thus, the polarity of the signal (Fig. 1) is an indicator of whether the sensor is experiencing compressive or tensile stresses.

For experiment A, we show a plan view of the final deformation pattern after the experiment (Fig. 2A) and a representative cross section (Fig. 2B). We use a color code in Figures 1 and 2 to illustrate fault development, in order to show (1) the faults' first appearance on the surface and the respective sensor response (Fig. 1A), and (2) their respective location in the caldera (Fig. 2).

The final surface deformation is complex, with many small faults (Fig. 2A). However, the overall pattern is consistent with the results obtained by Kennedy et al. (2004). Our crosssectional data (Fig. 2B) are also consistent with observations made by Kennedy et al. (2004). Inner faults are outward dipping, whereas outer faults are inward dipping. The set of inner faults is complex with many subsurface branches. The outer faults accommodated significant displacement on both sides and do not exhibit branching.

In summary, there is a clear correlation between stress perturbations, as recorded by our sensors during the course of an experiment, and fault development at the surface. Most notably, the large early trough in the signal is followed shortly by the first appearance of the main inner fault at the surface.

\section{FAULT EVOLUTION}

Despite the different run times, the two experiments are broadly comparable in terms of fault development and caldera evolution (Figs. $1 \mathrm{~A}$ and $1 \mathrm{~B})$. In both cases, the center sensor was the first to record significant events, namely a very large drop in the signal followed by a large peak. The west sensor exhibited very similar signals for both experiments, showing activity and instability near the end. For the east sensor, in experiment $\mathrm{B}$ there were very few perturbations compared to experiment A. This may be due to the fact that only a small amount of faulting developed on the eastern side of the caldera in experiment B. The style of collapse in the two experiments is very similar.

Fault nucleation processes are intimately related to stress perturbations. Faults are localized, irreversible ruptures. They form as a response to decompression of the magma chamber. Fault nucleation and propagation therefore produce a local, sudden stress drop. Our sensors record stress changes; thus, perturbations from the equilibrium state of the sensors are associated with fault nucleation sequences. This hypothesis is supported by the excellent correlation between (1) periods of large deviations relative to background in the sensor recordings and (2) fault formation observed at the surface. The correlation is spatial as well as temporal; when a fault appears at the surface, it is always the closest sensor that records significant variations. Furthermore, the sensors' response to stress variations decreases rapidly with distance, reinforcing the idea that the largest observed signals from a particular sensor are generated by faults forming closest to that sensor. It is thus possible to follow the stages of collapse from the signals in Figure 1. The collapse is initiated along an inner fault in the central area, consistent with major changes in the center sensors stress signals, while the outer sensors record nothing. The outer faults form asymmetrically; they start nucleating on one side before propagating to the other. This behavior is particularly visible in experiment $\mathrm{A}$, for which our visual observations suggest that collapse is initiated on the east side and then propagates to the west. This is again consistent with the data in Figure 1A where the east sensor records high stress changes beginning at $\sim 70 \mathrm{~s}$, while the west sensor does not record any instability until $\sim 110 \mathrm{~s}$.

We observe two distinct faulting patterns in the stress signal (Fig. 1). On one hand, the appearance of inner faults at the surface are preceded by a large, single peak in the sensor signal. By contrast, outer faults are not associated with any stress deviation before they appear on the surface, but they are followed by intense stress fluctuations. These contrasting stress patterns can be explained by distinct fault dynamics.

Inner faults propagate from the top of the magma chamber upward, whereas outer faults nucleate at the surface and propagate downward. This difference has been well documented (e.g., Roche et al., 2000; Kennedy et al., 2004; Acocella, 2007; Burchardt and Walter, 2010). It is confirmed in our experiments by observing how the amount of displacement accommodated by each fault varies with depth (see the Data Repository). The direction of propagation therefore explains why inner faults are recorded in the stress signal before they are visible at the surface, while outer faults exhibit stress perturbations only after they nucleate at the surface and propagate downward.

Inner and outer faults also exhibit two distinct growth modes (see the Data Repository). The large and abrupt peaks associated with inner faults suggest a rapid and sudden fault development. By contrast, outer faults produced several smaller peaks in the stress signal for a longer period. This indicates slower, more incremental fault growth.

By indicating when faults nucleate, our sensor data give us insight on where and when earthquakes occur during subsidence. The center sensor records sudden, large stress changes, suggesting en masse caldera collapse at an early stage of caldera evolution. These data resemble those for collapse at Mount Katmai (Alaska, USA) in A.D. 1912 and Mount Pinatubo (Philippines) in 1991 (Stix and Kobayashi, 2008). In these natural collapses, large amounts of seismic energy were suddenly released about halfway through the eruptions. The largest signals we observed in our experiments are the first very large drops recorded by the center sensor in both experiments. This would thus correspond to the largest seismic events, followed later by smallermagnitude earthquakes, corresponding to events recorded by the east and west sensors. In our experiments, the largest events occurred after $<10 \%$ of the reservoir volume was evacuated, as opposed to midway through the climactic eruption sequence as observed at Mounts Katmai and Pinatubo. This is due to the different aspect ratios involved (roof thickness / magma chamber diameter). Our experiments had an aspect ratio of 0.23 whereas Mounts Katmai and Pinatubo have aspect ratios of 2.0 and 2.4, respectively. At higher aspect ratios, faults form later (Roche et al., 2000), delaying seismic events.

Stix and Kobayashi (2008) showed that this sudden, en masse collapse behavior contrasts strongly with a longer, more continuous style of collapse, as observed at Miyakejima (Japan; Geshi et al., 2002) in A.D. 2000, and Bárðarbunga (Iceland; Gudmundsson et al., 2016) in A.D. 2014-2015. This latter style of collapse involves (1) basaltic magma as opposed to the more silicic magmas of Mounts Katmai and Pinatubo, and (2) slower magma evacuation rates $\left(1.7 \times 10^{2}\right.$ and $1.2 \times 10^{2} \mathrm{~m}^{3} \mathrm{~s}^{-1}$ for Miyakejima and Bárðarbunga, respectively, compared to $2.2 \times 10^{5}$ and $3.6 \times 10^{5} \mathrm{~m}^{3} \mathrm{~s}^{-1}$ for Mounts Katmai and Pinatubo, respectively). The end result is a protracted and progressive style of collapse. Future experimental work could easily model this behavior and examine detailed stress perturbations under these conditions. 


\section{FAULT PROPAGATION}

By focusing on the timing of both the first sharp drop in the sensor signal and the associated fault's appearance at the surface, we can estimate the rate of fault propagation from the magma chamber to the surface. First, we measure the time delay $\Delta t$ between the beginning of the drop in the sensor signal and the fault's appearance at the surface. Inner faults nucleate on top of the magma chamber and propagate upward. Knowing the depth of the top of the magma chamber $h$, we can then compute the model propagation rate $R_{\text {model }}=h / \Delta t$, which is $0.023 \pm 0.005 \mathrm{~m} \mathrm{~s}^{-1}$ for experiment $\mathrm{A}$ and $0.00168 \pm 0.00004 \mathrm{~m} \mathrm{~s}^{-1}$ for experiment B. We then scale back to natural speeds using $R_{\text {nature }}$ $=R_{\text {model }} / R^{*}$, where $R^{*}$ is the propagation rate scaling ratio given by $R^{*}=L^{*} T^{*-1}$. This scaling up produces fault propagation rates for natural systems of $3.8 \mathrm{~m} \mathrm{~s}^{-1}$, based on experiment $\mathrm{A}$, and $0.28 \mathrm{~m} \mathrm{~s}^{-1}$, based on experiment B. A higher evacuation rate therefore yields a higher fault propagation rate.

We can now apply these propagation rates to natural settings at Mounts Katmai and Pinatubo and compare our estimates to real seismic data. Propagation rates depend on evacuation rates, hence to choose the appropriate propagation rate for natural systems, we scale our experimental evacuation rates $E_{\text {model }}$ back to natural values $E_{\text {nature }}$ using $E_{\text {nature }}=E_{\text {model }} / E^{*}$ and the scaling ratio $E^{*}=L^{* 3} T^{*-1}$ (see Scaling Relations section). Values for $E_{\text {nature }}$ are $2.3 \times 10^{6} \mathrm{~m}^{3} \mathrm{~s}^{-1}$ and 4.6 $\times 10^{5} \mathrm{~m}^{3} \mathrm{~s}^{-1}$ based respectively on experiments $\mathrm{A}$ and $\mathrm{B}$. The value from experiment $\mathrm{B}$ is similar to observed evacuation rates at Mounts Katmai and Pinatubo $\left(2.2-3.6 \times 10^{5} \mathrm{~m}^{3} \mathrm{~s}^{-1}\right)$. Hence we apply a fault propagation rate of $0.28 \mathrm{~m} \mathrm{~s}^{-1}$ from experiment $\mathrm{B}$ to natural systems.

In the case of Mount Katmai, the top of the magma chamber was $4-5 \mathrm{~km}$ beneath the surface (Hildreth and Fierstein, 2000). Based on this depth and our chosen fault propagation rate of $0.28 \mathrm{~m} \mathrm{~s}^{-1}$, we obtain a time interval of 238-298 min for faults nucleating at the top of the magma chamber to reach the surface. This time scale can be compared with the occurrence of earthquakes at Mount Katmai. The largest earthquakes occurred on 8 June 1912 between 0611 and $1300 \mathrm{~h} \mathrm{UTC}$, representing an elapsed time of $409 \mathrm{~min}$. This interval is comparable to our experimental data and scaling analysis, suggesting that the major caldera-forming fault system at Mount Katmai was established and complete, from the top of the magma chamber to the surface, within $6.8 \mathrm{~h}$, resulting in caldera subsidence.

For Mount Pinatubo, the top of the magma chamber was $\sim 6 \mathrm{~km}$ deep (Mori et al., 1996). According to our analysis, it would then take $357 \mathrm{~min}$ for a fault to propagate all the way to the surface. During the climactic eruption on 15 June 1991, the largest seismic events of M5 and greater occurred from 0739 to $1225 \mathrm{~h} \mathrm{UTC}$, yielding a total elapsed time of $286 \mathrm{~min}$. However, the bulk of the seismic energy was released over a comparatively short interval of $51 \mathrm{~min}$ stretching from 1041 to $1132 \mathrm{~h}$ UTC. This observation suggests that both the fault propagation rate and magma evacuation rate were unusually high during this time. This is not surprising, because the evacuation rate likely undergoes substantial variations during such eruptions.

Despite the aspect ratio difference, the elevated evacuation rates in our experiments and for our natural examples (Mounts Katmai and Pinatubo) indicate a specific sequence of fault growth. The principal inner faults, which form rapidly, contrast with the longer durations and time scales of the outer faults. This dichotomy may be explained as a drawn-out response of the outer faults to sudden, large-scale fault movement in the central region of the caldera. Furthermore, significant seismicity may occur under certain conditions after the climactic eruption. In our experiments, all stress perturbations and faulting ceased when the pump was turned off. In nature, however, some further magma evacuation may be expected to occur after the large eruption from a series of smaller eruptions, subsurface magma drainage, or both. A certain threshold may be reached, which causes further subsidence and associated earthquakes. This was observed at both Mounts Katmai and Pinatubo.

\section{CONCLUDING REMARKS}

Using piezoelectric sensors in a series of analogue caldera collapse experiments, we were able to document stress perturbations of en masse caldera collapses similar to natural events such as at Mount Katmai in 1912 and Mount Pinatubo in 1991. Our results provide insight on the timing, location, and evolution of fault nucleation. This new and original experimental technique may be used to model other kinematic behaviors. We also estimated the propagation rate of early inner faults. This type of information is essential for our understanding of seismicity and fault development during caldera formation and, ultimately, our ability to assess and mitigate hazards in such settings.

\section{ACKNOWLEDGMENTS}

We thank Joan Martí, Nobuo Geshi, Valerio Acocella, and an anonymous reviewer for their constructive comments. We would also like to thank Jason Coumans for his help in setting up these experiments. This work was funded by Discovery and Accelerator grants to JS from the Natural Sciences and Engineering Research Council of Canada.

\section{REFERENCES CITED}

Acocella, V., 2007, Understanding caldera structure and development: An overview of analogue models compared to natural calderas: Earth-Science Reviews, v. 85 , p. 125-160, https://doi.org /10.1016/j.earscirev.2007.08.004.

Burchardt, S., and Walter, T.R., 2010, Propagation, linkage, and interaction of caldera ring-faults: Comparison between analogue experiments and caldera collapse at Miyakejima, Japan, in 2000: Bulletin of Volcanology, v. 72, p. 297-308, https://doi.org/10.1007/s00445-009-0321-7.

Coumans, J.P., and Stix, J., 2016, Caldera collapse at near-ridge seamounts: An experimental investigation: Bulletin of Volcanology, v. 78, p. 70-89, https://doi.org/10.1007/s00445-016-1065-9.

Geshi, N., Shimano, T., Chiba, T., and Nakada, S., 2002, Caldera collapse during the 2000 eruption of Miyakejima Volcano, Japan: Bulletin of Volcanology, v. 64, p. 55-68, https://doi.org/10.1007 /s00445-001-0184-z.

Gudmundsson, M.T., et al., 2016, Gradual caldera collapse at Bárdarbunga volcano, Iceland, regulated by lateral magma outflow: Science, v. 353, aaf8988, https://doi.org/10.1126/science.aaf8988.

Hildreth, W., and Fierstein, J., 2000, Katmai volcanic cluster and the great eruption of 1912: Geological Society of America Bulletin, v. 112, p. 1594 1620, https://doi.org/10.1130/0016-7606(2000) 112<1594:KVCATG >2.0.CO;2.

Hoek, E., Kaiser, P.K., and Bawden, W.F., 1995, Support of Underground Excavations in Hard Rock: Rotterdam, Netherlands, A.A. Balkema, 215 p.

Kennedy, B., Stix, J., Vallance, J.W., Lavallée, Y., and Longpré, M.-A., 2004, Controls on caldera structure: Results from analogue sandbox modeling: Geological Society of America Bulletin, v. 116, p. 515-524, https://doi.org/10.1130/B25228.1.

Kennedy, B.M., Jellinek, A.M., and Stix, J., 2008, Coupled caldera subsidence and stirring inferred from analogue models: Nature Geoscience, v. 1, p. 385-389, https://doi.org/10.1038/ngeo206.

Mori, J., Eberhart-Phillips, D., and Harlow, D.H., 1996, Three-dimensional velocity structure at Mount Pinatubo: Resolving magma bodies and earthquake hypocenters, in Newhall, C.G., and Punongbayan, R.S., eds., Fire and Mud: Eruptions and Lahars of Mount Pinatubo, Philippines: Quezon City, Philippines, Philippine Institute of Volcanology and Seismology, and Seattle, Washington, University of Washington Press, p. 371-382.

Roche, O., and Druitt, T.H., 2001, Onset of caldera collapse during ignimbrite eruptions: Earth and Planetary Science Letters, v. 191, p. 191-202, https://doi.org/10.1016/S0012-821X(01)00428-9.

Roche, O., Druitt, T.H., and Merle, O., 2000, Experimental study of caldera formation: Journal of Geophysical Research, v. 105, p. 395-416, https:// doi.org/10.1029/1999JB900298.

Sanford, A.R., 1959, Analytical and experimental study of simple geologic structures: Geological Society of America Bulletin, v. 70, p. 19-52, https://doi .org/10.1130/0016-7606(1959)70[19:AAESOS]2 $.0 . \mathrm{CO} ; 2$.

Schultz, R.A., 1996, Relative scale and the strength and deformability of rock masses: Journal of Structural Geology, v. 18, p. 1139-1149, https:// doi.org/10.1016/0191-8141(96)00045-4.

Stix, J., and Kobayashi, T., 2008, Magma dynamics and collapse mechanisms during four historic caldera-forming events: Journal of Geophysical Research, v. 113, B09205, https://doi.org/10.1029 /2007JB005073.

Manuscript received 25 July 2017

Revised manuscript received 21 September 2017

Manuscript accepted 25 September 2017

Printed in USA 